\title{
Serine/Threonine-Protein Kinase Nek1
}

National Cancer Institute

\section{Source}

National Cancer Institute. Serine/Threonine-Protein Kinase Nek1. NCI Thesaurus. Code C132118.

Serine/threonine-protein kinase Nek1 (1258 aa, 143 kDa) is encoded by the human NEK1 gene. This protein plays a role in cilia assembly, protein phosphorylation and cell division. 